\title{
Active and Robust Composite Films Based on Gelatin and Gallic Acid Integrated with Microfibrillated Cellulose
}

\author{
Yinghua Luo ${ }^{1}$, Yanbei $\mathrm{Wu}^{2, *}$, Yali Wang ${ }^{2}$ and Liangli (Lucy) Yu ${ }^{3} \mathbb{D}$ \\ 1 College of Food Science and Nutritional Engineering, National Engineering Research Centre for Fruits and \\ Vegetables Processing, Key Laboratory of Storage and Processing of Fruits and Vegetables, Ministry of \\ Agriculture, Engineering Research Centre for Fruits and Vegetables Processing, Ministry of Education, \\ China Agricultural University, Beijing 100083, China; luoyinghua@cau.edu.cn \\ 2 School of Food and Health, Beijing Technology and Business University, Beijing 100048, China; \\ wyali1125@163.com (Y.W.) \\ 3 Department of Nutrition and Food Science, University of Maryland, College Park, MD 20742, USA; \\ lyu5@umd.edu \\ * Correspondence: yanbeiwu@btbu.edu.cn
}

Citation: Luo, Y.; Wu, Y.; Wang, Y.; $\mathrm{Yu}, \mathrm{L}$. Active and Robust Composite Films Based on Gelatin and Gallic Acid Integrated with Microfibrillated Cellulose. Foods 2021, 10, 2831. https://doi.org/10.3390/ foods10112831

Academic Editor: Soottawat Benjakul

Received: 10 October 2021

Accepted: 10 November 2021

Published: 17 November 2021

Publisher's Note: MDPI stays neutral with regard to jurisdictional claims in published maps and institutional affiliations.

Copyright: (c) 2021 by the authors. Licensee MDPI, Basel, Switzerland. This article is an open access article distributed under the terms and conditions of the Creative Commons Attribution (CC BY) license (https:/ / creativecommons.org/licenses/by/ $4.0 /)$

\begin{abstract}
Background: Gelatin is a renewable, biodegradable, and inexpensive food polymer. The insufficient mechanical and functional properties of gelatin-based films (GBF) restrict their commercial application in food packaging. This work proposed a facile strategy to prepare an active and robust GBF that has the potential to be used in food packaging. Methods: A strong and active GBF was prepared based on the principle of supramolecular chemistry via the incorporation of gallic acid (GA) as an active crosslinking agent and of microfibrillated cellulose (MFC) as a reinforcing agent. Results: Under the appropriate concentration (1.0 wt \%), MFC was evenly dispersed in a gelatin matrix to endow the film with low surface roughness and compact structure. Compared with the GF, the tensile strength and elongation at break of the resultant film reached $6.09 \mathrm{MPa}$ and $213.4 \%$, respectively, representing the corresponding improvement of $12.8 \%$ and $27.6 \%$. Besides, a significantly improved water vapor barrier (from $3.985 \times 10^{-8}$ to $3.894 \times 10^{-8} \mathrm{~g} \cdot \mathrm{m}^{-1} \cdot \mathrm{Pa}^{-1} \cdot \mathrm{s}^{-1}$ ) and antioxidant activity (from $54.6 \%$ to $86.4 \%$ for ABTS radical scavenging activity; from $6.0 \%$ to $89.1 \%$ for DPPH radical scavenging activity) of GBFs were also observed after introducing the aromatic structure of GA and nano-/microfibrils in MFC. Moreover, the UV blocking performance and thermal stability of GGF and GGCFs were also enhanced. Conclusions: this work paves a promising way toward facile preparation of multifunctional GBFs that have great potential to be used in fabricating active and safe food packaging materials for food preservation.
\end{abstract}

Keywords: gelatin; gallic acid; active film; microfibrillated cellulose; reinforcement

\section{Introduction}

In the food industry, petroleum-based plastic film has been the frontrunner for decades now due to its low price and high stability [1]. However, the huge consumption of plastic food packaging materials has caused serious "white pollution", which leads to increasing threats to human health and the ecosystem [2]. Thus, it poses a pressing need for developing green packaging materials based on biodegradable and renewable biopolymers, e.g., polysaccharides and proteins. Gelatin, a film-forming biomaterial derived from animal meat production byproducts [3], has been widely used in preparing food packaging materials with good biodegradability in recent years due to its low cost, excellent filmforming properties, renewability, biocompatibility, high transparency, etc. [4,5].

However, gelatin has the inherent drawback of brittle nature (low strength and flexibility) owing to its low water resistance caused by its hydrophilicity [6,7]; thus, its wide application as a food packaging film material is limited. Given this, the modification of gelatin films (GFs) is essential for improving their application performance. Aldehydes [8-10], 
polyphenols [11,12], and polysaccharides $[13,14]$ are the most widely used modification agents. Besides, various hydrophobic compounds such as fats, oils, and waxes have been incorporated into gelatin networks to improve their water barrier properties, thus enabling the full utilization of these networks for food packaging applications [15,16]. Among them, aldehydes are the most widely used modification reagents since aldehyde-containing groups can react with amino groups to form stable Schiff base covalent bonds [17,18], thus improving the crosslinking degree of gelatin molecules. Owing to this beneficial effect, the introduction of aldehydes at a low concentration can enhance the thermal stability and mechanical properties of GFs. Nowadays, food safety is attracting more and more serious attention; the safety of these highly active aldehyde reagents, especially of glutaraldehyde that features cytotoxicity, has been highly concerning [19]; modification reagents must be carefully selected when used in food packaging films. As for the modification of GF using wax, the modified GF had dissatisfactory mechanical strength [15]. Hence, fabricating gelatin-based films (GBFs) that are both safe and robust is still a research challenge.

In addition to covalent crosslinking, the formation of multipoint hydrogen bonds between the modification reagents and gelatin molecules can also endow the GBFs with improved mechanical properties and thermal stability. Polyphenol-containing abundant phenolic hydroxyl groups can play the aforementioned role. Besides, polyphenol has excellent and attractive health-related properties, e.g., antioxidant, antibacterial and antitumor activities [20]. In addition to generating multipoint hydrogen bonds with gelatin molecules to form a more stable spatial structure, polyphenol can endow the crosslinked film materials with considerable antioxidant activity to reduce the oxidative degradation of food during storage. Meanwhile, it also lowers the risk of antioxidants addition to food during production and improves the safety of packaging films. In view of this, grape seed extracts and pine needle extracts containing abundant polymeric tannins were incorporated into gelatin films to prepare active gelatin-based films for food packaging [21-23]. In general, a food packaging film must be robust enough to withstand possible mechanical damage during food processing, storage and distribution. However, it has been reported that it is not sufficient to meet the requirements of food packaging materials by only relying on the multipoint hydrogen bonds between polyphenols and gelatin to enhance the mechanical properties of GBFs [6]. Hence, it is essential to propose a new strategy to improve the mechanical properties of the GBFs incorporated with polyphenols.

Microfibrillated cellulose (MFC), as a kind of renewable product, is well-known for its high elastic modulus and tensile strength as a mechanical reinforcement phase [24]. MFC is a form of nanocellulose in which the outer layer of the fibers has been shucked off via mechanical shearing, exposing the fibril bundles. The fibrils in MFC are much smaller in diameter compared to the original fibers and can form a network or a web-like structure [25]. More importantly, the microfibrils in MFC have a diameter in nanometers and length in micrometers, which makes them long and thin. This high aspect ratio makes the high-strength MFC useful in applications such as reinforcement of composites, films, and barriers. For instance, MFC can be incorporated into biopolymer-based films to improve their mechanical strength and ability to block water vapor permeation $[24,26]$. Besides, MFC is a renewable and biodegradable material, and the packaging industry is increasingly using renewable and biodegradable materials [27]. Therefore, these beneficial properties of the MFC fiber can help end-users in achieving lightweight and robust packaging solutions. MFC is supposed to be used to enhance the functions of GBFs. Herein, a facile strategy based on the principle of supramolecular chemistry was proposed for fabricating a strong and active GBF via the incorporations of gallic acid (GA) as an active crosslinking agent and MFC as a reinforcing agent. Specifically, the mechanical properties of the GBFs, as well as their structural features, microscopic morphology, optical properties, thermal stability, water vapor permeability, antioxidant properties, and crosslinking mechanism were determined. The supramolecular polymer network was established via forming multiple noncovalent interactions, thereby enhancing the mechanical strength of the resultant film. 
This strategy paves a new way toward producing high-performance and safe GBFs for active food packaging and preservation.

\section{Materials and Methods}

\subsection{Materials}

The gelatin (type B, limed-hide hydrolysis) used was purchased from Sinopharm Chemical Reagent Co., Ltd. (Shanghai, China). Its average molecular weight was about 100,000 g/mol. Glycerol (analytical grade) was provided by Sinopharm Chemical Reagent Co., Ltd. (Shanghai, China). Gallic acid was analytical grade and obtained from Tianjin Kemiou Chemical Reagent Co., Ltd. (Tianjin, China). Microfibrillated cellulose (1.8 wt\%) was provided by China National Pulp and Paper Research Institute Co., Ltd. (Beijing, China), while 1,1-diphenyl-2-picrylhydrazyl (DPPH) was obtained from TCI Chemicals (Shanghai, China) and 2,2'-azinobis-3-ethylbenzthiazoline-6-sulfonate (ABTS) was obtained from Biotopped Life Science (Beijing, China). Methanol was analytical grade and provided by Macklin Biochemical Technology Co., Ltd. (Shanghai, China).

\subsection{Preparation of Gelatin-Based Films}

Gelatin-based films (GBFs) were prepared via a solution casting method [7,28]. Firstly, $10.0 \mathrm{~g}$ of gelatin, $4.0 \mathrm{~mL}$ of glycerol ( $40 \mathrm{w} / \mathrm{v} \%$ of gelatin), and $0.5 \mathrm{~g}$ gallic acid (GA, $5.0 \mathrm{wt} \%$ based on gelatin) were dissolved in $96 \mathrm{~mL}$ distilled water. After continuous stirring at $60{ }^{\circ} \mathrm{C}$ for $30 \mathrm{~min}$, microfibrillated cellulose (MFC, $0.5 \mathrm{wt} \%, 1.0 \mathrm{wt} \%, 3.0 \mathrm{wt} \%$ and $5.0 \mathrm{wt} \%$ of gelatin, based on the dry basis) was added to the gelatin solution dropwise and the solution $\mathrm{pH}$ was adjusted to around 4.0 using formic acid. After that, the solution was heated at $60{ }^{\circ} \mathrm{C}$ for $60 \mathrm{~min}$ with intense stirring. Besides, a pure gelatin film solution was prepared following the same method with no additions of gallic acid and MFC for comparison. Another gelatin film solution was prepared using a similar procedure with no introduction of MFC for clarifying the role of MFC. All the as-prepared solutions were ultrasonically degassed and then cast on leveled Teflon plates $(14 \mathrm{~cm} \times 14 \mathrm{~cm})$ and dried at room temperature for $72 \mathrm{~h}$. After peeling off from the plates, the dried films were air-conditioned at $25{ }^{\circ} \mathrm{C}$ and $50 \% \mathrm{RH}$ for $48 \mathrm{~h}$ for further analyses. These film samples were designated as GF (neat gelatin film), GGF (gelatin and GA composite film), GGCF-1, GGCF-2, GGCF-3, and GGCF-4 (gelatin and GA mixed with MFC at $0.5 \mathrm{wt} \%, 1.0 \mathrm{wt} \%$, $3.0 \mathrm{wt} \%$ and $5.0 \mathrm{wt} \%$, respectively).

\subsection{Structure Characterizations}

The GBFs were analyzed using a Fourier-transform infrared spectrometer equipped with an attenuated total reflectance accessory (TENSOR 27, Brook, Germany). Each infrared spectrum (wavenumber, 4000 600 600 4000 $\mathrm{cm}^{-1}$ ) was collected at a resolution of $4 \mathrm{~cm}^{-1}$. The X-ray diffraction (XRD) patterns of the GBFs were obtained using an XRD diffractometer (X-D6, Persee, Beijing, China) in the diffraction angles of $2 \theta=5 \sim 85^{\circ}$ with a scanning speed of $0.4^{\circ} / \mathrm{min}$ using $\mathrm{Cu} \mathrm{K \alpha}$ radiation $(\lambda=1.54 \mathrm{~nm})$ with a nickel monochromator operating at the voltage of $36 \mathrm{kV}$ and the current of $20 \mathrm{~mA}$. The thermal stability of each GBF was evaluated using a thermogravimetric analyzer (TGA/DSC 3+, Mettler Toledo, Zurich, Switzerland). For this, about $10 \mathrm{mg}$ of film sample was heated from 30 to $800{ }^{\circ} \mathrm{C}$ at the heating rate of $10^{\circ} \mathrm{C} / \mathrm{min}$ under the $\mathrm{N} 2$ atmosphere. The surface and cross-sections of the GBFs were investigated using a field emission scanning electron microscope (FESEM, Apreo 2C SEM, Thermo Scientific, Waltham, MA, USA) in the high-vacuum mode with the acceleration voltage of $5 \mathrm{kV}$. The surface roughness of the film samples was observed using an atomic force microscope (AFM, AFM5100W, Hitachi, Tokyo, Japan) [29].

\subsection{Optical Properties Analyses}

The surface color of the film samples was measured using a color measurement instrument (SC-80C, Jingyi Kangguang, Beijing, China) with the standard white color plate $(\mathrm{L}=95.41, \mathrm{a}=-0.46, \mathrm{~b}=2.01)$ as the background. The illuminant used was a D65 standard 
light source, and the field of view was $10^{\circ}$. The total color difference $(\Delta \mathrm{E})$ was calculated according to Equation (1):

$$
\Delta \mathrm{E}=\sqrt{\Delta \mathrm{L}^{2}+\Delta \mathrm{a}^{2}+\Delta \mathrm{b}^{2}}
$$

where $\Delta \mathrm{L}, \Delta \mathrm{a}$, and $\Delta \mathrm{b}$ are the difference between each color value of the film sample and the standard plate, respectively [30].

The UV-vis spectra of GBFs were recorded using a UV-vis spectrophotometer (TU1810, Persee, Beijing, China). In particular, the optical properties of the films, including the UV barrier property and transparency, were assessed by recording light transmittance percentages at $280 \mathrm{~nm}\left(\mathrm{~T}_{280}\right)$ and $660 \mathrm{~nm}\left(\mathrm{~T}_{660}\right)$, respectively. Moreover, the appearances of different films were recorded using a digital camera [31].

\subsection{Determination of Physical Properties}

Water vapor permeability (WVP) was measured using a gravimetric method according to the method described by Riahi et al. [31] and Yu et al. [22] with a slight modification. The film samples (the diameter was $50 \mathrm{~mm}$ ) were mounted on top of a glass jar (depth $=95 \mathrm{~mm}$; inner diameter $=30 \mathrm{~mm}$ ) containing $50 \mathrm{~mL}$ of distilled water and sealed in such a way that the evaporation of water from the cup took place only through the sample film. The assembled glass jars were weighed and stored in a desiccator controlled at $25^{\circ} \mathrm{C}$ and $25 \%$ $\mathrm{RH}$. The weight of the jar was measured at $0,1,2,4,6,9,12 \mathrm{~h}$ at $25^{\circ} \mathrm{C}$, and the weight loss of the jar versus time was plotted to measure the water vapor transmission rate (WVTR, $\left.\mathrm{g} / \mathrm{m}^{2} \mathrm{~s}\right)$ from the slope of the plot. The WVP $\left(\mathrm{g} \cdot \mathrm{m} / \mathrm{m}^{2} \cdot \mathrm{Pa} \cdot \mathrm{s}\right)$ of the film was calculated using Equation (2):

$$
\mathrm{WVP}=\frac{\mathrm{WVTR} \times \mathrm{L}}{\Delta \mathrm{P}}
$$

where $\mathrm{L}$ represents the mean film thickness $(\mathrm{m})$ and $\Delta \mathrm{P}$ is the partial water vapor pressure difference (Pa) between the two sides of the film; $\Delta \mathrm{p}$ was calculated according to the formula: $\Delta \mathrm{p}=\mathrm{Ps} \times(\mathrm{R} 1-\mathrm{R} 2)$, where $\mathrm{Ps}$ is the saturation vapor pressure of water at $25^{\circ} \mathrm{C}$ (Pa), R1 is the relative humidity inside the jar $(100 \%)$, and $\mathrm{R} 2$ is the relative humidity in the desiccator $(25 \%)$. The surface water contact angle (WCA) of each GBF was measured with a contact angle meter (JC2000DM, Beijing Zhongyi Kesin Technology Co., Ltd., Beijing, China). Ten microliters of deionized water were used to test the surface contact angle of the GBFs. Dissolution of the GBFs in distilled water was simply evaluated by adding a piece of film $(0.5 \mathrm{~cm} \times 3.0 \mathrm{~cm})$ into a reagent bottle containing $10 \mathrm{~mL}$ of distilled water. After swelling for $12 \mathrm{~h}$, the appearance of the film was recorded using a digital camera before/after shaking well.

The thickness of the GBFs was measured at three random points using a digital micrometer with an accuracy of $1 \mu \mathrm{m}$, and the average value was used. The tensile strength (TS) and percentage elongation at break (EB) of the GBFs $(25 \mathrm{~mm} \times 150 \mathrm{~mm})$ were analyzed following the ASTM D 882-88 standard method using a universal testing machine (AI7000SN, Gotech, Dongguan, China). The apparatus ran in the tensile mode, with the initial grip separation of $15 \mathrm{~mm}$ and the cross-head speed of $500 \mathrm{~mm} / \mathrm{min}$.

\subsection{Antioxidant Activity Evaluation}

The antioxidant capacity of the GBFs was evaluated with a UV-vis spectrophotometer (TU-1810, Persee, Beijing, China) according to the ABTS radical and DPPH radical scavenging methods described by Roy et al. [1] with a slight modification. A GBF in the amount of $0.1 \mathrm{~g}$ was placed in a tube filled with $5.0 \mathrm{~mL}$ of methanol solution $(70 \%, v / v)$ to extract the active compounds. After incubation at $25^{\circ} \mathrm{C}$ for $24 \mathrm{~h}$, the supernatant was collected to determine the radical scavenging activities of ABTS and DPPH.

For the ABTS radical scavenging activity assay, $7.00 \mathrm{mM}$ of the aqueous ABTS solution and $2.45 \mathrm{mM}$ of the $\mathrm{K} 2 \mathrm{~S} 2 \mathrm{O} 8$ solution were blended with a 1:1 volume ratio and stood for $16 \mathrm{~h}$ in the dark. The as-prepared ABTS radical solution was then diluted with methanol until the absorbance value at $734 \mathrm{~nm}$ was about $0.70 \pm 0.02$. After that, $1.0 \mathrm{~mL}$ of the GBF 
extract solution and $3.0 \mathrm{~mL}$ of this diluted solution were blended thoroughly and incubated in the dark at $25{ }^{\circ} \mathrm{C}$ for $10 \mathrm{~min}$ before testing absorption at $734 \mathrm{~nm}$. The ABTS radical scavenging activity (\%) was calculated according to Equation (3):

$$
\text { Scavenging activity } / \%=\frac{\mathrm{A}_{0}-\mathrm{A}_{\mathrm{T}}}{\mathrm{A}_{0}} \times 100
$$

where $A_{0}$ and $A_{T}$ represent the absorbance of the ABTS solution of the control and the GBF sample, respectively.

For the DPPH radical scavenging activity measurement, $4 \mathrm{mg}$ of DPPH were dissolved in $100 \mathrm{~mL}$ of methanol to prepare the DPPH methanolic solution. After that, $4.0 \mathrm{~mL}$ of this solution and $2.0 \mathrm{~mL}$ of the GBF extract solution were mixed well and stood in the dark for $30 \mathrm{~min}$, and then the absorbance at $517 \mathrm{~nm}$ was measured. As a control, the DPPH solution was prepared without adding the film solution, which was replaced with the methanol solution. The radical scavenging activity (\%) of DPPH was calculated according to Equation (4):

$$
\text { Scavenging activity } / \%=\frac{A_{c}-A_{s}}{A_{C}} \times 100
$$

where $A_{c}$ and $A_{s}$ represent the absorbance for the control and the GBF sample solution, respectively.

\subsection{Statistical Analysis}

The experimental data were shown as the means \pm standard deviations from at least three parallel experiments. The data were subjected to the one-way ANOVA analysis followed by Tukey's post hoc test for statistical analysis. The mean values were statistically significant if the probability values were less than $0.05(p<0.05)$.

\section{Results and Discussion}

\subsection{Structure Features of MFC}

As mentioned above, microfibrillated cellulose (MFC) is a kind of cellulose in which the outer layer of the fibers has been shucked off using mechanical shearing, exposing the fibril bundles with amorphous and crystalline domains (Figure 1a). The structure features of MFC were first clarified using FTIR, XRD, SEM, and particle size measurement. As shown in Figure 1b, the pristine MFC presents some typical peaks for cellulose: hydrogenbonded $-\mathrm{OH}$ stretching at $3342 \mathrm{~cm}^{-1},-\mathrm{CH}$ stretching at $2900 \mathrm{~cm}^{-1},-\mathrm{CH}_{2}$ bending at $1425 \mathrm{~cm}^{-1},-\mathrm{C}-\mathrm{O}$ stretching at $1058 \mathrm{~cm}^{-1}$, and $-\mathrm{CH}$ bending or $-\mathrm{CH}_{2}$ stretching at $900 \mathrm{~cm}^{-1}$. These typical peaks indicate the amorphous structure [32]. Figure 1c illustrates the X-ray diffraction pattern for MFC powder, which is a typical diffractogram reported for semicrystalline polymeric materials. The overlapping peaks positioned at diffraction angles $2 \theta$ of $\sim 15.8^{\circ}$ corresponding to the amorphous region and another diffraction peak positioned at a diffraction angle $2 \theta$ of $\sim 22.2^{\circ}$ corresponding to the crystalline region were observed [20].

To clarify natural aggregates of cellulose nano- and microfibrils in the MFC, SEM observation of powdery MFC was conducted. Figure 1d illustrates the representative SEM micrographs of the MFC used in this work. Low-aspect-ratio fiber aggerates and high-aspect-ratio fibril aggregates could be observed. The average diameter of MFC was calculated to be $0.12 \mu \mathrm{m}$. This confirmed the structural feature of MFC, ensuring the potential functionalities that can be offered by MFC in the reinforcement of GBF. MFC has a high affinity to itself and the materials with many hydroxyl groups, especially water. Owing to the dominance of hydroxyl groups, polymeric MFC is very reactive with water [33]. As a result, in an aqueous MFC solution, nano- and microfibrils might tend to aggregate into fiber bundles in larger sizes via both intra- and intermolecular hydrogen bonds, which can be verified by the larger particle size of MFC in water shown in Figure 1e. This feature may endow MFC with a dose-effect relationship between its additive amount and the reinforcing effect when it is used as a reinforcer in the fabrication of GBF. 


\section{(a)}

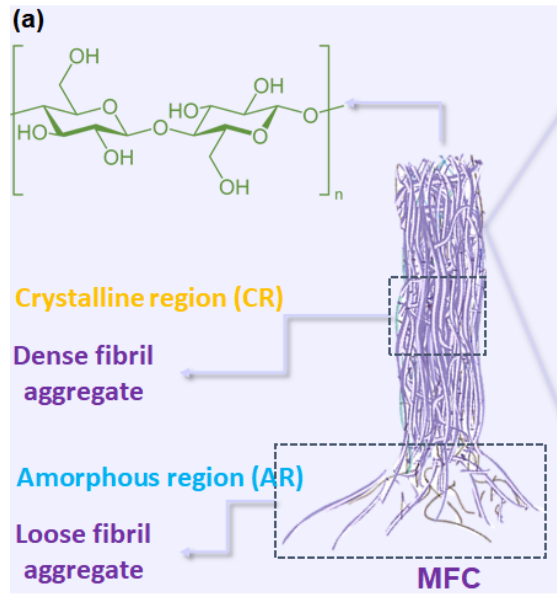

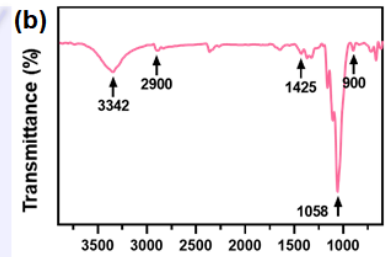

Wavenumber $\left(\mathrm{cm}^{-1}\right)$

(d)

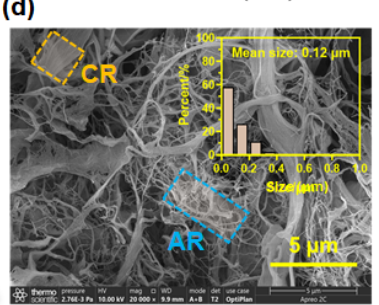

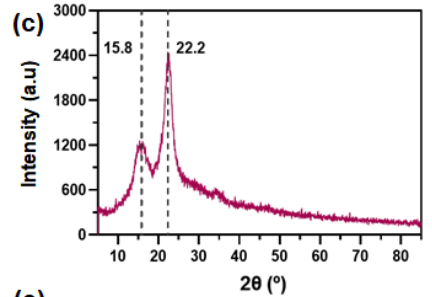

(e)

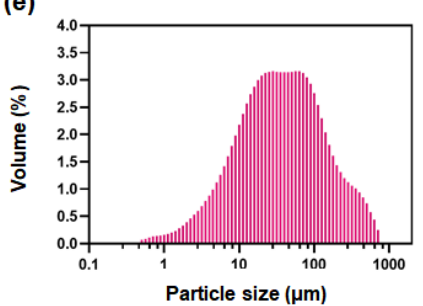

Figure 1. Schematic illustration (a) with permission from Springer 2019 [34], FTIR spectrum (b), XRD spectrum (c), SEM image (d) and particle size (e) of microfibrillated cellulose (MFC).

\subsection{FTIR and XRD Analyses of GBFs}

The FTIR spectra of the GBFs are shown in Figure 2a. The pure gelatin film (GF) had characteristic peaks at $3316 \mathrm{~cm}^{-1}$ and $2935 \mathrm{~cm}^{-1}$. They are respectively assigned to the $\mathrm{O}-\mathrm{H}$ and $\mathrm{C}-\mathrm{H}$ stretching vibrations in the gelatin structure [35]. At $1642 \mathrm{~cm}^{-1}$, there was a peak ascribed to the amide-I vibration of the $\mathrm{C}=\mathrm{O}$ group connected to $\mathrm{COO}^{-}$. For the peak at $1550 \mathrm{~cm}^{-1}$, it was assigned to the amide-II vibration because of the $\mathrm{N}-\mathrm{H}$ bending and $\mathrm{C}-\mathrm{N}$ stretching. Furthermore, an amide-III vibration band appeared at $1235 \mathrm{~cm}^{-1}$, suggesting the vibrations of $\mathrm{C}-\mathrm{N}$ and $\mathrm{N}-\mathrm{H}$ groups of bound amides in the plane [36]. For GF, the amide-I, amide-II, and amide-III vibration bands' positions were similar to those of gelatin reported in other works. Moreover, the spectra showed the amide-V band at $670 \mathrm{~cm}^{-1}$, which may be the feature of low-molecular-weight peptides in gelatin [31]. The peak at $1037 \mathrm{~cm}^{-1}$ was due to the in-plane bending vibration of the -OH group of glycerol [37]. Notably, it can be seen that the characteristic absorption peaks of GA and MFC overlapped in the spectra of gelatin and glycerol. Thus, the spectra of the GF, GGF, and GGCFs are highly identical. When the GA and MFC were added, there was no significant difference observed in the band position, indicating that no new chemical bonding formed in the GBFs.
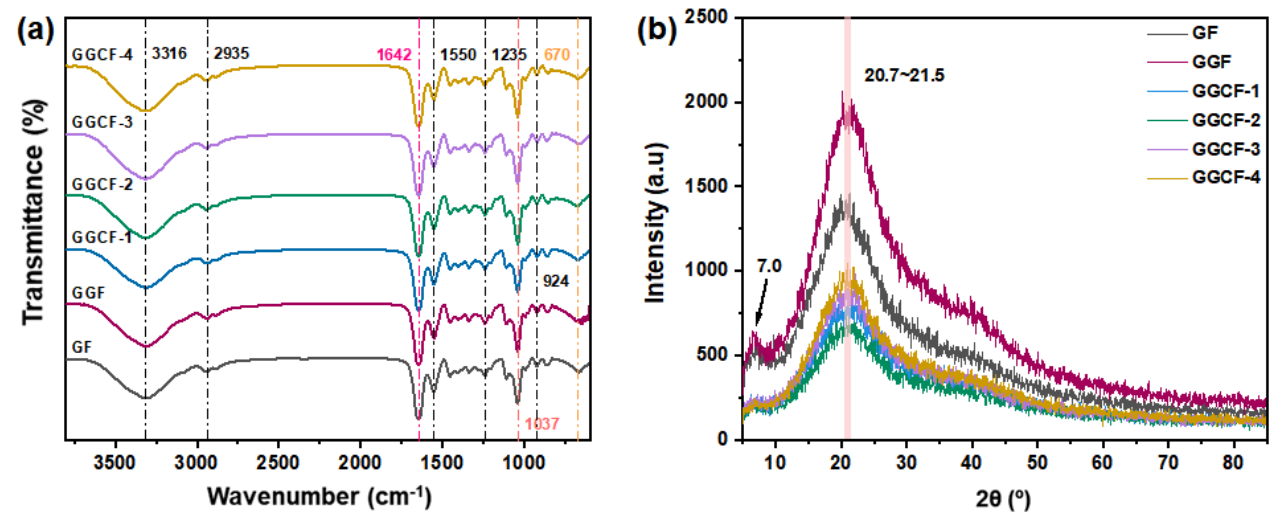

Figure 2. FTIR (a) and XRD (b) spectra of gelatin-based films (GBFs).

The change in the crystallinity of the GBFs with the addition of GA and MFC was evaluated using XDR. Figure $2 b$ shows the XRD patterns of the different GBFs. The neat gelatin film (GF) without GA and MFC exhibited a representative amorphous structure with a broad peak in the $2 \theta$ range of $10.0 \sim 25.0^{\circ}$ [38]. The XRD pattern of the GGCFs did not present a distinct characteristic peak of GF and GGF with the introduction of MFC, which might be ascribed to the overlapping effect of the gelatin matrix on MFC 
(diffraction angle $2 \theta$ of $\sim 15.8^{\circ}$ and $\sim 22.2^{\circ}$ ) with low concentrations ( $0.5 \mathrm{wt} \%$ to $5.0 \mathrm{wt} \%$ ). Furthermore, the integrated intensity of the diffraction peak with an angle $2 \theta$ of $\sim 8^{\circ}$ for GGCFs was lower than that for GGF and GF, suggesting that a decreased amount of triplehelix configuration was present within the GGCF matrix compared to the GF and GGF matrix [29]. This decreased formation of triple-helix configurations might be attributed to the higher molecular weight of the GGCF system compared to GF and GGF systems, which might restrict molecular mobility during film formation [29]. This also laterally indicated that introducing MFC might improve the stability of the GF's network structure.

\subsection{Microstructure of GBFs}

The SEM images of the surface and cross-sections of the GBFs are shown in Figure 3. It can be observed that some pores existed on the surface of GF, and the pores still existed when GA was introduced. With the addition of MFC, the number of pores gradually decreased, and the pores were hard to observe when the concentration of MFC was not higher than $3.0 \mathrm{wt} \%$ of gelatin. When $5.0 \mathrm{wt} \%$ of MFC was incorporated in the GBF, there were a lot of pores on the surfaces of GBFs (GGCF-4), which might be due to the aggregation of excess MFC. Meanwhile, the film structure became rather tanglesome and discontinuous, which might harm the mechanical properties of the film. As presented in the cross-sectional micrographs (Figure 3(a-2)-(f-2)), there were many cracks in GF and GGF. With the introduction of MFC, the cracks gradually disappeared in the cross-sections. This suggested that MFC performed an obvious filling effect on the GBFs, resulting in the more compact structure of GBFs. This might lead to the increase in tensile strength of GBFs.

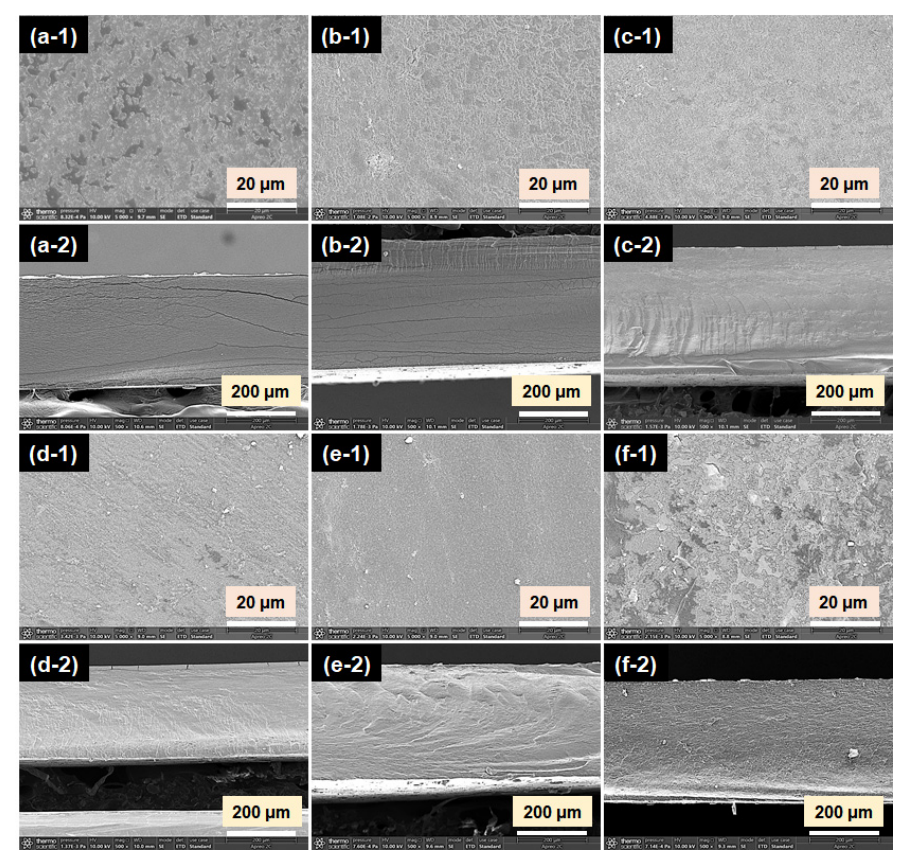

Figure 3. SEM micrographs of surfaces (1) and cross-sections (2) of GBFs: GF (a); GGF (b); GGCF-1 (c); GGCF-2 (d); GGCF-3 (e); GGCF-4 (f).

Furthermore, AFM observation of the GBF was conducted to assess its surface roughness (Figure 4). The measured roughness value ( $\mathrm{Ra}$ ) of the GBF matched the SEM observations. A higher Ra value means higher roughness [39]. For GF, the Ra value was up to $35.9 \mathrm{~nm}$, indicating the high roughness of the film. The surface roughness of GBFs increased first as the concentration of MFC increased and then decreased as the MFC addition was up to $5.0 \mathrm{wt} \%$ of gelatin. The Ra was highest for $5.0 \mathrm{wt} \%$ because of the aggregation of MFC in the polymer matrix. Similarly, an aggregation effect of cellulose nanofibrils (CNF) at a high concentration had also been observed in gelatin films [40] and starch nanocomposites [41]. In light of the above results and as inspired by the XRD results, excessive MFC would also 
have the possibility to decrease the molecular mobility of the film's components, thereby leading to a reduction in the elongation at break of the GGCFs.

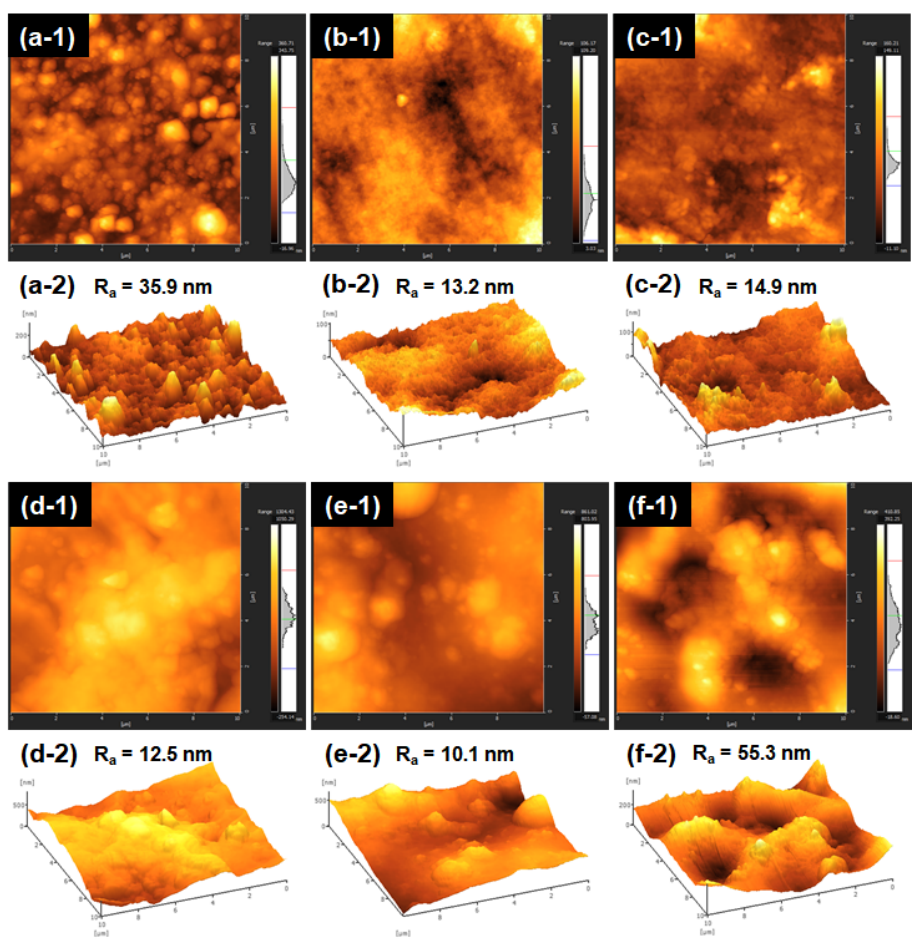

Figure 4. AFM micrographs of surfaces of GBFs with a size of $10 \mu \mathrm{m} \times 10 \mu \mathrm{m}$ : GF (a); GGF (b); GGCF-1 (c); GGCF-2 (d); GGCF-3 (e); GGCF-4 (f).

\subsection{Surface Color and Optical Properties}

The physical appearance of the packaging film is a key parameter, especially the color, which usually dominates the visibility of the packaged product and consumer's acceptance [12]. With the color of the GBFs shown in Table 1 , the $L^{*}$ value displays an obvious decrease $(p<0.05)$, whereas the $\mathrm{b}^{*}$ and $\Delta \mathrm{E}$ values significantly increased $(p<0.05)$ with the addition of GA in the films. After incorporating MFC, the $\mathrm{L}^{*}$ value further decreased while the $b^{*}$ value increased and the $a^{*}$ value had no significant change. With more MFC incorporated, the $\mathrm{L}^{*}, \mathrm{a}^{*}, \mathrm{~b}^{*}$ did not change significantly overall, but the $\triangle \mathrm{E}$ value generally increased. The results indicated that introducing MFC made the GBFs yellower, which can be visually observed from the appearances of GBFs shown in Figure 5a. In short, GA had a significant effect on the color of the GBF, resulting in a darker and yellower color. As was reported by Riahi et al., the $L^{*}$ and $b^{*}$ values of protein-based films would be markedly increased after the introduction of plant extracts [31], and the $\Delta \mathrm{E}$ value of the films would also be greatly increased, which was in accord with our results.

Table 1. Apparent color and light transmittance of GBFs.

\begin{tabular}{ccccccc}
\hline Films & $\mathbf{L}^{*}$ & $\mathbf{A}^{*}$ & $\mathbf{B}^{*}$ & $\boldsymbol{\Delta E}$ & $\mathbf{T}_{\mathbf{2 8 0}} / \mathbf{\%}^{*}$ & $\mathbf{T}_{\mathbf{6 6 0}} / \mathbf{\%}^{\mathbf{0}}$ \\
\hline GF & $89.90 \pm 0.44^{\mathrm{a}}$ & $-0.84 \pm 0.31^{\mathrm{a}}$ & $8.29 \pm 0.58^{\mathrm{c}}$ & 8.30 & 0.4 & 42.0 \\
GGF & $88.16 \pm 0.44^{\mathrm{b}}$ & $-0.69 \pm 0.43^{\mathrm{a}}$ & $10.77 \pm 0.20^{\mathrm{b}}$ & 11.25 & 0.3 & 53.0 \\
GGCF-1 & $87.86 \pm 0.16^{\mathrm{b}}$ & $-0.63 \pm 0.32^{\mathrm{a}}$ & $12.08 \pm 0.52^{\mathrm{ab}}$ & 12.47 & 0.3 & 49.4 \\
GGCF-2 & $87.30 \pm 0.29^{\mathrm{bc}}$ & $-0.30 \pm 0.58^{\mathrm{a}}$ & $12.30 \pm 0.88^{\mathrm{ab}}$ & 12.98 & 0.3 & 53.1 \\
GGCF-3 & $86.78 \pm 0.02^{\mathrm{c}}$ & $-0.90 \pm 0.34^{\mathrm{a}}$ & $12.71 \pm 0.13^{\mathrm{a}}$ & 13.62 & 0.3 & 47.5 \\
GGCF-4 & $87.41 \pm 0.31^{\mathrm{bc}}$ & $-0.72 \pm 0.24^{\mathrm{a}}$ & $12.78 \pm 0.32^{\mathrm{a}}$ & 13.30 & 0.3 & 46.5 \\
\hline
\end{tabular}

${ }^{*}$ Data are expressed as the means \pm SD $(n=3)$, and the different lowercase superscripts in the same column indicate significant differences $(p<0.05)$. 


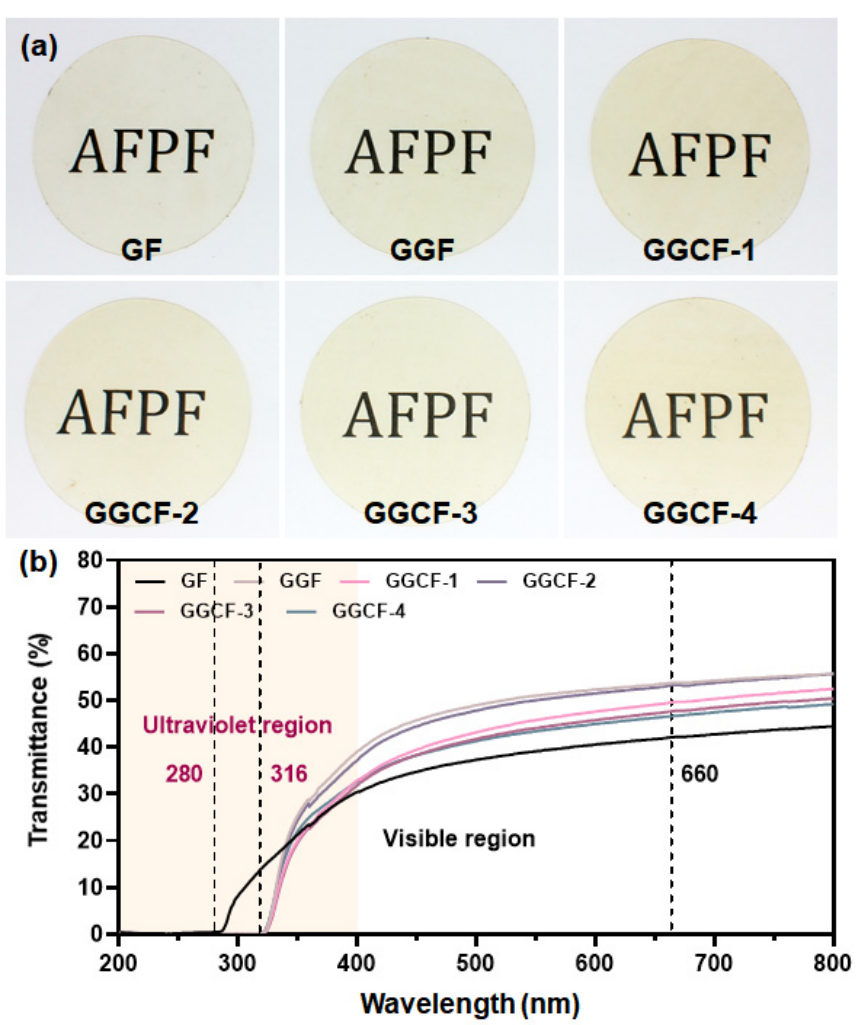

Figure 5. Appearance (a) and UV-vis spectra (b) of GBFs; AFPF: active food packaging film.

Next, the light transmittance of GBFs was recorded in the region of 200-800 nm, aiming to investigate the UV barrier and transparency properties. Figure $5 \mathrm{~b}$ shows the UV-vis spectra of different GBFs. The polypeptide chains of gelatin contain aromatic amino acids (tyrosine and phenylalanine) that can absorb UV radiation [42]. At $280 \mathrm{~nm}$, all the GBFs presented a negligible transmittance value (Table 1). With the addition of GA, the resistance to UV light transmission of GBFs in the UV region 280-316 nm was further improved due to the aromatic ring structure with anti-ultraviolet properties [6]. The addition of MFC showed no negative impact on the UV light absorption function of GBFs. In the visible region of 400-800 nm, the GF showed the lowest transmission of light while GGF exhibited the highest transmission of light. With the incorporation of MFC, the visible light transmittance of GBFs had a slight decrease (Table 1). This might be due to the difference in the dispersion and aggregation of MFC in different GBFs. In short, the addition of GA could considerably improve the UV resistance and visible light transmittance of the GBFs. Meanwhile, the introduction of MFC would not cause obvious damage to the above properties.

\subsection{WVP and WCA of GBFS}

As is well-known, moisture migration is an important factor that can affect the shelf life of food products [43]; thus, WVP of the GBFs was further measured. Compared with GF, the addition of GA resulted in an increment in the WVP of the GBFs (Table 2). However, there was an obvious decrease in WVP for the GBFs (GGCFs) incorporated with MFC. When $5.0 \mathrm{wt} \%$ MFC was incorporated, WVP of a GBF (GGCF-4) was much lower than that of GF. This indicated that the capability to block water vapor permeation was improved. Similarly, Ortiz et al. also reported that the GBFs had lower WVP after the introduction of MFC. This effect could be attributed to a successful dispersion of nanofibers within the protein matrix that helped to construct a more tortuous path for the passage of water molecules through the film [44]. Meanwhile, the introduced MFC might provide more intermolecular crosslinking in the film matrix via forming hydrogen bonding and hydrophobic interactions [23]. This feature would show unpleasant impacts on some 
hydrophilic domains in the film matrix, thereby leading to the declined hydrophilicity of the films [22].

Table 2. Water vapor permeability (WVP) and water contact angle (WCA) of GBFs.

\begin{tabular}{ccc}
\hline Films & WVP $\left(\times \mathbf{1 0}^{-\mathbf{8}} \mathbf{g} \cdot \mathbf{m}^{-\mathbf{1}} \cdot \mathbf{P a} \mathbf{1}^{-\mathbf{1}} \mathbf{s}^{-\mathbf{1}}\right)^{*}$ & WCA (deg.) $^{*}$ \\
\hline GF & $3.985 \pm 0.001^{\mathrm{abc}}$ & $69.30 \pm 1.41^{\mathrm{b}}$ \\
GGF & $4.379 \pm 0.225^{\mathrm{ab}}$ & $75.16 \pm 0.49^{\mathrm{a}}$ \\
GGCF-1 & $3.768 \pm 0.194^{\mathrm{bc}}$ & $76.35 \pm 0.81^{\mathrm{a}}$ \\
GGCF-2 & $3.894 \pm 0.082^{\mathrm{bc}}$ & $79.25 \pm 1.61^{\mathrm{a}}$ \\
GGCF-3 & $4.093 \pm 0.079^{\mathrm{ab}}$ & $79.48^{\mathrm{b}} \pm 2.21^{\mathrm{a}}$ \\
GGCF-4 & $3.634 \pm 0.189^{\mathrm{c}}$ & $80.22^{\mathrm{a}} \pm 2.27^{\mathrm{a}}$ \\
\hline
\end{tabular}

* Data are expressed as the means \pm SD $(n=3)$, and the different lowercase superscripts in the same column indicate significant differences $(p<0.05)$.

Table 2 shows that the WCA of the GF was $69.30^{\circ}$, which was increased to $75.16^{\circ}$ through adding GA. When only $0.50 \mathrm{wt} \%$ MFC was added to a GBF, the WCA further increased to $76.35^{\circ}$. As the concentration of MFC further increased, the WCA was also continuously increased, which could be up to $80.22^{\circ}$ when $5.0 \mathrm{wt} \%$ MFC was introduced. This suggested that the introduction of MFC could lead to an increase in hydrophobicity of the GBFs, which was beneficial for improving the water vapor barrier property of GBFs to potentially protect the packaged products from putrefaction. Figure $\mathrm{S} 1$ also shows that the as-prepared GBFs could be completely dissolved in distilled water after swelling for $12 \mathrm{~h}$, which suggests the easy treatability of these GBFs.

\subsection{Mechanical Strength}

As was previously reported, the interactions of gelatin chains with other components, e.g., antioxidant substances, plasticizers, water, and reinforcing agents can markedly impact the mechanical properties of the resultant composite films [45]. Besides, the component content of these components can also play an important role in the mechanical properties of the resultant composite films. Herein, the mechanical properties of all the GBFs were determined, including tensile strength (TS) and elongation at break (EB). It can be seen in Figure 6 that the TS and EB of the GBF had no obvious change when the GA was added. After the introduction of MFC ( $0.5 \mathrm{wt} \%$ to $5.0 \mathrm{wt} \%)$, there was a significant increase in the TS of GGCFs while the EB of GGCFs (MFC-added films) increased first and then decreased. In particular, when the MFC concentration was set to be $0.50 \mathrm{wt} \%$ and $1.0 \mathrm{wt} \%$, the EB of the GBFs was higher than that of GF and GGF and could be up to about $200 \%$, which was much higher than that of the GBFs reinforced by other additives (Figure $6 \mathrm{c}$ and Table S1). After increasing the MFC concentration, the EB of GBFs decreased to be comparable with that of GF and GGF.

Overall, the introduction of MFC significantly improved the mechanical properties of the GBF incorporated with GA. This favorable combination of high TS and EB was mainly ascribed to the tough noncovalent interactions within the GGCF. The crystalline MFC molecules could result in the formation of rigid crosslinking domains in the gelatin matrix. The amorphous chains of MFC could just act as a soft constituent to keep the flexibility of the gelatin films. Besides, the hydrophilic MFC weakened the interaction between proteins, thereby reducing cohesion and increasing the plasticity of the blend matrix, so that the resulting GGCF had higher flexibility [46].

During the stretching process, the energy could be effectively dissipated by the synergistically improved dynamic hydrogen bonds, hydrophobic interactions and $\pi-\pi$ interactions in the GGCF (Figure 6d) [47] that could act as sacrificial bonds [48]. These multiple interfacial interactions aided the formation of a strengthened supramolecular network in these composites to update the adhesion and cohesion of the GGCF. In this work, the tensile strength of the GBFs was updated with the incorporation of MFC. However, in comparison with the traditional plastic materials, the GGCFs have no sufficiently strong mechanical properties, which needs to be ameliorated in the future, especially the TS. 

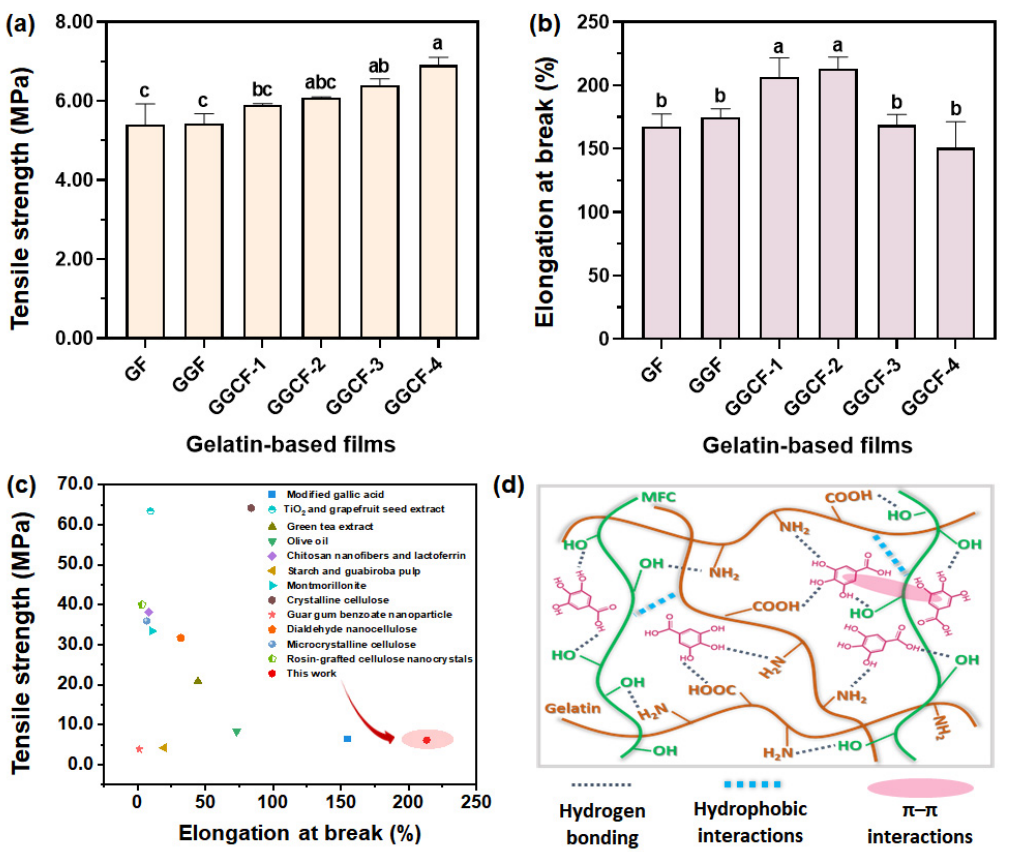

Figure 6. Tensile strength (a) and elongation at break (b) of the GBFs; (c) comparison of the mechanical strength of different GBFs; (d) the proposed reinforcing mechanism of MFC on the gelatin-based film. The results are expressed as the means \pm SD $(n=3)$, the columns marked with different lowercase letters are significantly different from each other at $p<0.05$.

\subsection{Thermal Stability}

The thermal stability of a GBF is very important for its practical application in complex environments. Figure 7 illustrates the thermal stability of various GBFs investigated using the TG-DSC measurement. There are three degradation stages for the thermal decomposition of GF. The first stage occurs below $100{ }^{\circ} \mathrm{C}$ and is mainly composed of weight loss due to the desorption of absorbed water [49]. In the second stage (from $100{ }^{\circ} \mathrm{C}$ to $300{ }^{\circ} \mathrm{C}$ ), there is a weight loss of $36 \%$ caused by the degradation of glycerol in the GBF [50]. In the final stage (from $300{ }^{\circ} \mathrm{C}$ to $550{ }^{\circ} \mathrm{C}$ ), peptide bonds and sidechain groups in amino acid residues are degraded. With a further increase in temperature, the gelatin matrix began to carbonize, which resulted in weight loss during the decomposition process [47].
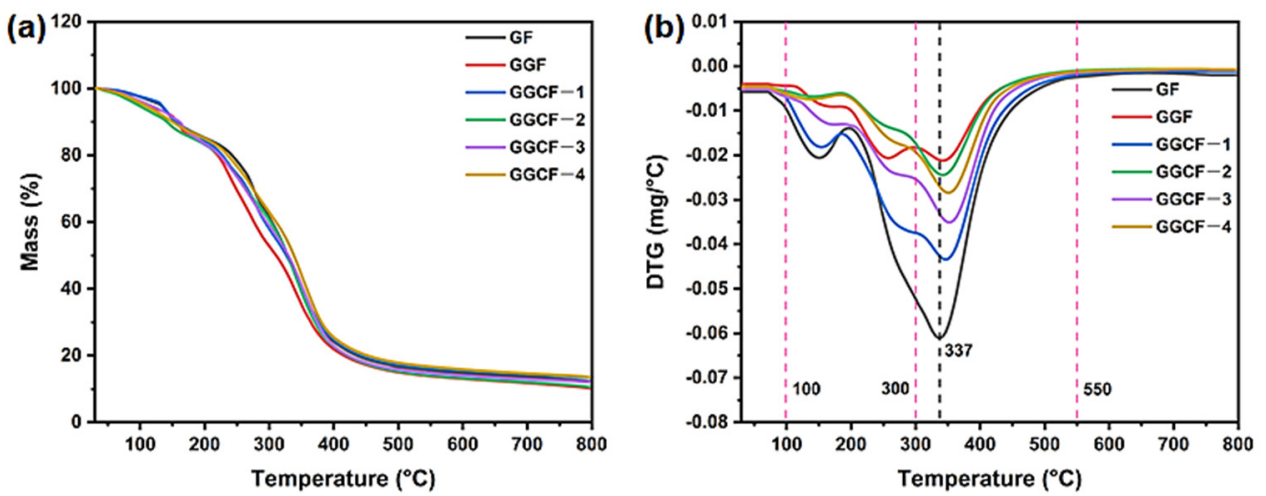

Figure 7. TG (a) and DTG curves (b) of GF, GGF, and different GGCFs.

The incorporation of GA and MFC led to the peak temperature $\left(\mathrm{T}_{\max }\right)$ of the GBF increasing from $337^{\circ} \mathrm{C}(\mathrm{GF})$ to $355^{\circ} \mathrm{C}$ (GGCF-3). This increment was associated with the formation of a compact char layer in the GBF matrix due to the presence of phenolic hydroxyl groups and aromatic char produced by GA at high temperatures. When the GA and MFC were heated to high temperatures, more carbon residue and char would be 
formed, causing a loss in the combustion heat of GBFs [51]. During the heating process, the GA and MFC contributed to the formation of the char layer, hindering the mass transfer and heat flow between the condensed phase and the combustible gas, thereby accelerating the dehydration and carbonization of the gelatin matrix [52]. Therefore, the GA and MFC prevented further erosion of the underlying gelatin matrix from heat flux caused by thermal decomposition, resulting in the improved thermal stability of GBFs [47]. The updated thermal stability of GBFs provides a promising prospect for the application of gelatin-based packaging materials in harsh environments.

\subsection{Antioxidant Activity}

The antioxidant ability of GBFs was evaluated using ABTS and DPPH free radical scavenging tests. Figure 8 a illustrates that the active compounds, particularly GA, should be released from the network structure of GBF in a methanol aqueous medium. Figure 8a illustrates that the GF performed moderate ABTS free radical scavenging activity while it showed weak DPPH free radical scavenging property (Figure 8b). GA was previously proven to possess remarkable antioxidant activities, including free radical scavenging capacity [20]. Thus, the scavenging effects of GBFs on the two kinds of free radicals were significantly improved with the introduction of GA. Moreover, a notable concentrationdependent change in ABTS free radical scavenging activity was observed when MFC $(1.0 \sim 5.0 \mathrm{wt} \%$ of gelatin) was integrated into the films. Gelatin is a well-known protein source for antioxidant hydrolysates [53] due to the presence of phenolic amino acids. According to the work reported by Guo et al., the neat gelatin film had weak DPPH free radical scavenging capacity [6], which was similar to the present DPPH free radical scavenging activity of GF. Moreover, it can be observed that the introduction of MFC showed no impact on the DPPH free radical scavenging capacity of GBFs. In comparison, the DPPH radical scavenging activity of polypropylene (PP)-based composite films was $73 \%$ when the BHT concentration was 3\% of the composite film [54]. Besides, the DPPH radical scavenging activity of fish skin gelatin film incorporated with BHT at the concentration of 200 ppm was not higher than $10 \%$ [55].
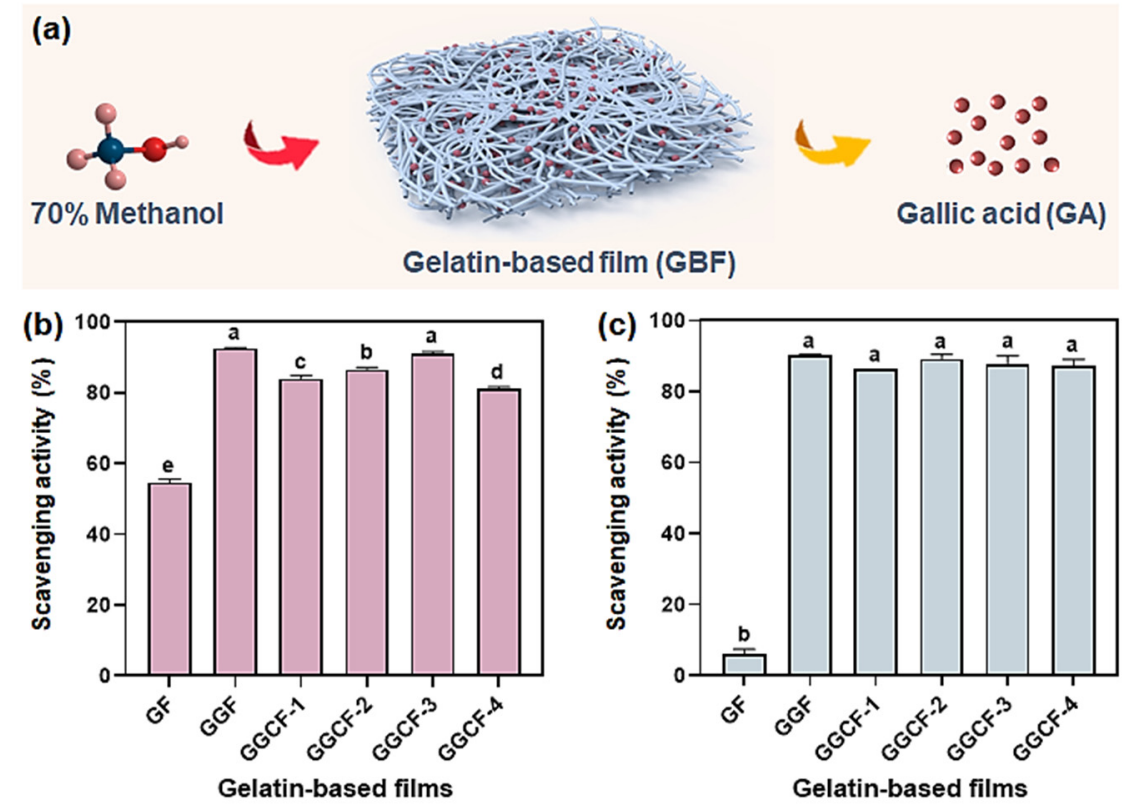

Figure 8. Schematic diagram of the release of GA from a GBF in an aqueous methanol solution (a); ABTS (b) and DPPH (c) radical scavenging capacities of GBFs. The results are expressed as the means $\pm \mathrm{SD}(\mathrm{n}=3)$, the columns marked with various lowercase letters are significantly different from each other at $p<0.05$. 
In summary, the abovementioned PP-based composite films had higher TS (up to $69 \mathrm{MPa}$ ) and EB (up to 704\%) than the as-prepared GBFs [54]. Some of the GBFs reinforced with other additives might have had higher TS (up to 64), but their EBs were generally much lower than those of the as-prepared GBFs (Table S1). Overall, in light of the aforementioned results, it was suggested that the antioxidant ability of GBFs incorporated with GA was favorable, and the introduction of MFC would not cause obvious negative effects and could improve the mechanical strength of GBFs when a suitable MFC concentration was employed, which is beneficial for the fabrication of active and robust GBFs. As-prepared GBFs show potential to be used as active edible food films or other active food packaging materials for food preservation.

\section{Conclusions}

In this work, a robust and active gelatin-based film (GBF) with improved UV-blocking ability, water vapor barrier and antioxidant activity was successfully fabricated. The interconnected crosslinking network was established in the gelatin matrix by integration with gallic acid (GA) and microfibrillated cellulose (MFC) via forming multiple noncovalent interactions between gelatin, GA, and MFC chains, including hydrogen bonds, hydrophobic interactions, and $\pi-\pi$ interactions. These interactions could act as dynamic sacrificial bonds to promote effective energy dissipation during stretching so that the resultant GBF had higher mechanical properties than a pure gelatin film (GF). With introducing MFC at a concentration of $1.0 \mathrm{wt} \%$, MFC was evenly dispersed in the gelatin matrix to endow the film with low surface roughness and compact structure, resulting in corresponding improvements of $12.8 \%$ for tensile strength and $27.6 \%$ for elongation at break relative to the neat gelatin film (GF). The UV-blocking performance, water vapor barrier, thermal stability, and antioxidant activity of GBFs were also significantly improved relative to the GF after introducing the aromatic structure of GA and nano-/microfibrils in MFC. This work paves a promising way toward the facile preparation of multifunctional GBFs that have great potential to be used in fabricating active and safe food packaging materials.

Supplementary Materials: The following are available online at https:/ / www.mdpi.com/article/10 $.3390 /$ foods10112831/s1, Table S1: Comparison of the reinforcing effect of different additives for the gelatin-based film (GBF). Figure S1: Dissolution of GBFs in distilled water.

Author Contributions: Conceptualization, methodology, Y.W. (Yanbei Wu); investigation, Y.L. (Yinghua Luo) and Y.W. (Yali Wang); writing-original draft preparation, Y.L. and Y.W.; writing-review and editing, Y.W. and L.Y.; supervision, L.Y. All authors have read and agreed to the published version of the manuscript.

Funding: Not applicable.

Institutional Review Board Statement: Not applicable.

Informed Consent Statement: Not applicable.

Data Availability Statement: The data presented in this study are available on request from the corresponding author.

Conflicts of Interest: The authors declare no conflict of interest.

\section{References}

1. Roy, S.; Rhim, J. Preparation of antimicrobial and antioxidant gelatin/curcumin composite films for active food packaging application. Colloids Surf. B Biointerfaces 2020, 188, 110761. [CrossRef]

2. Shen, M.; Song, B.; Zeng, G.; Zhang, Y.; Huang, W.; Wen, X.; Tang, W. Are biodegradable plastics a promising solution to solve the global plastic pollution? Environ. Pollut. 2020, 263, 114469. [CrossRef]

3. Ghorbani, K.; Kouchaki, S.; Sadeghi, N.; Eslamifarsani, E.; Rabbani, F.; Beyramysoltan, S. Distinguishing tissue origin of bovine gelatin in processed products using LC/MS technique in combination with chemometrics tools. Food Chem. 2020, $319,126302$.

4. Ahmad, M.; Benjakul, S.; Prodpran, T.; Agustini, T.W. Physico-mechanical and antimicrobial properties of gelatin film from the skin of unicorn leatherjacket incorporated with essential oils. Food Hydrocoll. 2012, 28, 189-199. [CrossRef] 
5. Bang, Y.-J.; Shankar, S.; Rhim, J.-W. In situ synthesis of multi-functional gelatin/resorcinol/silver nanoparticles composite films. Food Packag. Shelf Life 2019, 22, 100399. [CrossRef]

6. Guo, L.; Qiang, T.; Ma, Y.; Ren, L.; Zhu, C. Biodegradable Anti-Ultraviolet Film from Modified Gallic Acid Cross-linked Gelatin. ACS Sustain. Chem. Eng. 2021, 9, 8393-8401. [CrossRef]

7. Shankar, S.; Jaiswal, L.; Selvakannan, P.R.; Ham, K.S.; Rhim, J.W. Gelatin-based dissolvable antibacterial films reinforced with metallic nanoparticles. RSC Adv. 2016, 6, 67340-67352. [CrossRef]

8. Kwak, H.W.; Lee, H.; Park, S.; Lee, M.E.; Jin, H.J. Chemical and physical reinforcement of hydrophilic gelatin film with di-aldehyde nanocellulose. Int. J. Biol. Macromol. 2020, 146, 332-342. [CrossRef] [PubMed]

9. Park, J.; Nam, J.; Yun, H.; Jin, H.; Won, H. Aquatic polymer-based edible films of fish gelatin crosslinked with alginate dialdehyde having enhanced physicochemical properties. Carbohydr. Polym. 2021, 254, 117317. [CrossRef]

10. Scopel, B.S.; Pretto, G.L.; Corrêa, J.I.P.; Baldasso, C.; Dettmer, A.; Santana, R.M.C. Starch-leather waste gelatin films cross-linked with glutaraldehyde. J. Polym. Environ. 2020, 28, 1974-1984. [CrossRef]

11. Wu, J.; Chen, S.; Ge, S.; Miao, J.; Li, J.; Zhang, Q. Preparation, properties and antioxidant activity of an active film from silver carp (Hypophthalmichthys molitrix) skin gelatin incorporated with green tea extract. Food Hydrocoll. 2013, 32, 42-51. [CrossRef]

12. Rangaraj, V.M.; Rambabu, K.; Banat, F.; Mittal, V. Effect of date fruit waste extract as an antioxidant additive on the properties of active gelatin films. Food Chem. 2021, 355, 129631. [CrossRef]

13. Wang, H.; Ding, F.; Ma, L.; Zhang, Y. Edible films from chitosan-gelatin: Physical properties and food packaging application. Food Biosci. 2021, 40, 100871. [CrossRef]

14. Loo, C.P.Y.; Sarbon, N.M. Chicken skin gelatin films with tapioca starch. Food Biosci. 2020, 35, 100589. [CrossRef]

15. Syahida, N.; Fitry, I.; Zuriyati, A.; Hanani, N. Effects of palm wax on the physical, mechanical and water barrier properties of fish gelatin films for food packaging application. Food Packag. Shelf Life 2020, 23, 100437. [CrossRef]

16. Tongnuanchan, P.; Benjakul, S.; Prodpran, T. Structural, morphological and thermal behaviour characterisations of fish gelatin film incorporated with basil and citronella essential oils as affected by surfactants. Food Hydrocoll. 2014, 41, 33-43. [CrossRef]

17. Liu, J.; Zhang, L.; Liu, C.; Zheng, X.; Tang, K. Tuning structure and properties of gelatin edible films through pullulan dialdehyde crosslinking. LWT 2021, 138, 110607. [CrossRef]

18. Ding, W.; Wu, Y. Sustainable dialdehyde polysaccharides as versatile building blocks for fabricating functional materials: An overview. Carbohydr. Polym. 2020, 248, 116801. [CrossRef]

19. Ouyang, J.; Pu, S.; Wang, J.; Deng, Y.; Yang, C.; Naseer, S.; Li, D. Enzymatic hydrolysate of geniposide directly acts as cross-linking agent for enzyme immobilization. Process Biochem. 2020, 99, 187-195. [CrossRef]

20. Guo, L.; Qiang, T.; Ma, Y.; Ren, L.; Dai, T. Purification and characterization of hydrolysable tannins extracted from Coriaria nepalensis bark using macroporous resin and their application in gallic acid production. Ind. Crops Prod. 2021, $162,113302$. [CrossRef]

21. Wang, X.; Wang, Y.; Li, L.; Gu, Z.; Yu, X. Feasibility study of the naturally occurring dialdehyde carboxymethyl cellulose for biological tissue fixation. Carbohydr. Polym. 2015, 115, 54-61. [CrossRef] [PubMed]

22. Yu, Z.; Sun, L.; Wang, W.; Zeng, W.; Mustapha, A.; Lin, M. Soy protein-based films incorporated with cellulose nanocrystals and pine needle extract for active packaging. Ind. Crop. Prod. 2018, 112, 412-419. [CrossRef]

23. Shahbazi, Y. The properties of chitosan and gelatin films incorporated with ethanolic red grape seed extract and Ziziphora clinopodioides essential oil as biodegradable materials for active food packaging. Int. J. Biol. Macromol. 2017, 99, 746-753. [CrossRef]

24. Lavoine, N.; Desloges, I.; Dufresne, A.; Bras, J. Microfibrillated cellulose-Its barrier properties and applications in cellulosic materials: A review. Carbohydr. Polym. 2012, 90, 735-764. [CrossRef]

25. Liu, J.; Liu, C.; Zheng, X.; Chen, M.; Tang, K. Soluble soybean polysaccharide/nano zinc oxide antimicrobial nanocomposite films reinforced with microfibrillated cellulose. Int. J. Biol. Macromol. 2020, 159, 793-803. [CrossRef]

26. Cozzolino, C.A.; Cerri, G.; Brundu, A.; Farris, S. Microfibrillated cellulose (MFC): Pullulan bionanocomposite films. Cellulose 2014, 21, 4323-4335. [CrossRef]

27. Shaikh, S.; Yaqoob, M.; Aggarwal, P. An overview of biodegradable packaging in food industry. Curr. Res. Food Sci. 2021, 4, 503-520. [CrossRef]

28. Ma, W.; Tang, C.; Yin, S.; Yang, X.; Wang, Q.; Liu, F.; Wei, Z. Characterization of gelatin-based edible fi lms incorporated with olive oil. Food Res. Int. 2012, 49, 572-579. [CrossRef]

29. Quero, F.; Padilla, C.; Campos, V.; Luengo, J.; Caballero, L.; Melo, F.; Li, Q.; Eichhorn, S.J.; Enrione, J. Stress transfer and matrix-cohesive fracture mechanism in microfibrillated cellulose-gelatin nanocomposite films. Carbohydr. Polym. 2018, 195, 89-98. [CrossRef]

30. Ding, W.; Guo, S.; Liu, H.; Pang, X.; Ding, Z. Synthesis of an amino-terminated waterborne polyurethane-based polymeric dye for high-performance dyeing of biomass-derived aldehyde-tanned chrome-free leather. Mater. Today Chem. 2021, $21,100508$. [CrossRef]

31. Riahi, Z.; Priyadarshi, R.; Rhim, J.; Bagheri, R. Gelatin-based functional films integrated with grapefruit seed extract and TiO2 for active food packaging applications. Food Hydrocoll. 2021, 112, 106314. [CrossRef]

32. Yeo, J.; Kim, O.Y.; Hwang, S. The effect of chemical surface treatment on the fracture toughness of micro fi brillated cellulose reinforced epoxy composites. J. Ind. Eng. Chem. 2017, 45, 301-306. [CrossRef] 
33. Khazraji, A.C.; Robert, S. Self-Assembly and Intermolecular Forces When Cellulose and Water Interact Using Molecular Modeling. J. Nanomater. 2013, 2013, 745979. [CrossRef]

34. Larsson, P.A.; Riazanova, A.V.; Cinar Ciftci, G.; Rojas, R.; Øvrebø, H.H.; Wågberg, L.; Berglund, L.A. Towards optimised size distribution in commercial microfibrillated cellulose: A fractionation approach. Cellulose 2019, 26, 1565-1575. [CrossRef]

35. Kanmani, P.; Rhim, J.-W. Physical, mechanical and antimicrobial properties of gelatin based active nanocomposite films containing AgNPs and nanoclay. Food Hydrocoll. 2014, 35, 644-652. [CrossRef]

36. Pereda, M.; Ponce, A.G.; Marcovich, N.E.; Ruseckaite, R.A.; Martucci, J.F. Chitosan-gelatin composites and bi-layer films with potential antimicrobial activity. Food Hydrocoll. 2011, 25, 1372-1381. [CrossRef]

37. Shankar, S.; Teng, X.; Li, G.; Rhim, J.-W. Preparation, characterization, and antimicrobial activity of gelatin/ZnO nanocomposite films. Food Hydrocoll. 2015, 45, 264-271. [CrossRef]

38. Wang, W.; Wang, K.; Xiao, J.; Liu, Y.; Zhao, Y.; Liu, A. Performance of high amylose starch-composited gelatin films influenced by gelatinization and concentration. Int. J. Biol. Macromol. 2017, 94, 258-265. [CrossRef]

39. Mohammad, A.W.; Hilal, N.; Lim, Y.P.; Amin, I.N.H.M.; Raslan, R. Atomic force microscopy as a tool for asymmetric polymeric membrane characterization. Sains Malaysiana 2011, 40, 237-244.

40. Wang, W.; Liu, Y.; Jia, H.; Liu, Y.; Zhang, H.; He, Z.; Ni, Y.H. Effects of Cellulose Nanofibers Filling and Palmitic Acid Emulsions Coating on the Physical Properties of Fish Gelatin Films. Food Biophys. 2017, 12, 23-32. [CrossRef]

41. Hietala, M.; Mathew, A.P.; Oksman, K. Bionanocomposites of thermoplastic starch and cellulose nanofibers manufactured using twin-screw extrusion. Eur. Polym. J. 2013, 49, 950-956. [CrossRef]

42. Wang, Y.; Zhang, R.; Qin, W.; Dai, J.; Zhang, Q.; Lee, K.; Liu, Y. Physicochemical properties of gelatin films containing tea polyphenol-loaded chitosan nanoparticles generated by electrospray. Mater. Des. 2020, 185, 108277. [CrossRef]

43. Realini, C.E.; Marcos, B. Active and intelligent packaging systems for a modern society. Meat Sci. 2014, 98, 404-419. [CrossRef]

44. Ortiz, C.M.; Salgado, P.R.; Dufresne, A.; Mauri, A.N. Microfibrillated cellulose addition improved the physicochemical and bioactive properties of biodegradable films based on soy protein and clove essential oil. Food Hydrocoll. 2018, 79, 416-427. [CrossRef]

45. Li, J.; Miao, J.; Wu, J.; Chen, S.; Zhang, Q. Preparation and characterization of active gelatin-based films incorporated with natural antioxidants. Food Hydrocoll. 2014, 37, 166-173. [CrossRef]

46. Bitencourt, C.M.; Fávaro-Trindade, C.S.; Sobral, P.J.A.; Carvalho, R.A. Gelatin-based films additivated with curcuma ethanol extract: Antioxidant activity and physical properties of films. Food Hydrocoll. 2014, 40, 145-152. [CrossRef]

47. Li, K.; Jin, S.; Zhou, Y.; Luo, J.; Li, J.; Li, X.; Shi, S.Q.; Li, J. Bioinspired interface design of multifunctional soy protein-based biomaterials with excellent mechanical strength and UV-blocking performance. Compos. Part B 2021, 224, 109187. [CrossRef]

48. Jin, S.; Li, K.; Xia, C.; Li, J. Sodium alginate-assisted route to antimicrobial biopolymer film combined with aminoclay for enhanced mechanical behaviors. Ind. Crops Prod. 2019, 135, 271-282. [CrossRef]

49. Li, X.; Wei, Y.; Jiang, S.; Zhou, Y.; Li, J.; Li, K.; Shi, S.Q.; Li, J. Full Bio-Based Soy Protein Isolate Film Enhanced by Chicken Feather Keratin. Macromol. Mater. Eng. 2021, 306, 2100004. [CrossRef]

50. Zhao, S.; Wang, Z.; Pang, H.; Li, Z.; Zhang, W.; Zhang, S.; Li, J.; Li, L. Designing Biomimetic Microphase-Separated Motifs to Construct Mechanically Robust Plant Protein Resin with Improved Water-Resistant Performance. Macromol. Mater. Eng. 2020, 305, 1900462. [CrossRef]

51. You, X.; Wang, X.; Zhang, H.J.; Cui, K.; Zhang, A.; Wang, L.; Yadav, C.; Li, X. Supertough lignin hydrogels with multienergy dissipative structures and ultrahigh antioxidative activities. ACS Appl. Mater. Interfaces 2020, 12, 39892-39901. [CrossRef] [PubMed]

52. Zhang, X.; Liu, W.; Yang, D.; Qiu, X. Biomimetic supertough and strong biodegradable polymeric materials with improved thermal properties and excellent UV-blocking performance. Adv. Funct. Mater. 2019, 29, 1806912. [CrossRef]

53. Mendis, E.; Rajapakse, N.; Kim, S.-K. Antioxidant properties of a radical-scavenging peptide purified from enzymatically prepared fish skin gelatin hydrolysate. J. Agric. Food Chem. 2005, 53, 581-587. [CrossRef] [PubMed]

54. Fasihnia, S.H.; Peighambardoust, S.H.; Peighambardoust, S.J.; Oromiehie, A.; Soltanzadeh, M.; Peressini, D. Migration analysis, antioxidant, and mechanical characterization of polypropylene-based active food packaging films loaded with BHA, BHT, and TBHQ. J. Food Sci. 2020, 85, 2317-2328. [CrossRef]

55. Jongjareonrak, A.; Benjakul, S.; Visessanguan, W.; Tanaka, M. Antioxidative activity and properties of fish skin gelatin films incorporated with BHT and $\alpha$-tocopherol. Food Hydrocoll. 2008, 22, 449-458. [CrossRef] 